\title{
Thrust Stand for Electric Propulsion Performance Evaluation*
}

\author{
T.E. Markusic $\dagger$, J.E. Jones $\ddagger$, and M.D. Cox ${ }^{\diamond}$ \\ NASA Marshall Space Flight Center, Huntsville, AL 35763
}

\begin{abstract}
An electric propulsion thrust stand capable of supporting thrusters with total mass of up to $125 \mathrm{~kg}$ and $1 \mathrm{mN}$ to $1 \mathrm{~N}$ thrust levels has been developed and tested. The mechanical design features a conventional hanging pendulum arm attached to a balance mechanism that transforms horizontal motion into amplified vertical motion, with accommodation for variable displacement sensitivity. Unlike conventional hanging pendulum thrust stands, the deflection is independent of the length of the pendulum arm, and no reference structure is required at the end of the pendulum. Displacement is measured using a non-contact, optical linear gap displacement transducer. Mechanical oscillations are attenuated using a passive, eddy-current damper. An on-board microprocessor-based level control system, which includes a two axis accelerometer and two linear-displacement stepper motors, continuously maintains the level of the balance mechanism - counteracting mechanical "zero drift" during thruster testing. A thermal control system, which includes heat exchange panels, thermocouples, and a programmable recirculating water chiller, continuously adjusts to varying thermal loads to maintain the balance mechanism temperature, to counteract thermal drifts. An in-situ calibration rig allows for steady state calibration both prior to and during thruster testing. Thrust measurements were carried out on a well-characterized $1 \mathrm{~kW}$ Hall thruster; the thrust stand was shown to produce repeatable results consistent with previously published performance data.
\end{abstract}

$\alpha_{1} \quad$ main beam angular deflection

$\alpha_{2} \quad$ secondary beam angular deflection

Nomenclature

$d_{i j} \quad$ displacement vector between points $i$ and $j$

$F \quad$ applied force

$\mathbf{r}_{i} \quad$ position vector between points $\mathrm{i}$ and $\mathrm{j}$

g acceleration due to gravity

$l_{i j} \quad$ length of member between points $i$ and $j$

m mass

m. thruster mass

T/W thrust to weight ratio

\footnotetext{
* This material is declared a work of the U.S. Government and is not subject to copyright protection in the United States.

$\dagger$ Research Aerospace Engineer, Propulsion Research Center.

$\ddagger$ Research Aerospace Engineer, Propulsion Research Center.

$\checkmark$ Aerospace Engineer, Science Directorate.
} 


\section{Introduction}

Electric propulsion (EP) systems provide high specific impulse, but low thrust, relative to chemical systems. Whereas chemical rocket thrust is generally measured using load cells[20], the low thrust to weight ratio (T/W) of EP devices precludes the use of load cells; current EP thrust measurement devices are more akin to sensitive laboratory mass scales, wherein the physical displacement of one of the mechanical members in the balance system is used to infer the applied force. Calibrated displacement thrust stands have been widely implemented for EP performance evaluation. The most common configurations are: the hanging pendulum, the inverted pendulum, and the torsional pendulum.

The conventional hanging pendulum has the advantages of simplicity of construction (low cost) and high stability. However, high sensitivity can only be attained with a long pendulum arm, which may be impractical if the test facility (vacuum chamber) is small. Therefore, conventional hanging pendulum thrust stands have been primarily used to test high T/W EP devices, such as electrothermal arcjets and microwave electrothermal thrusters [4,6]. Also, a separate reference structure is required, to support the displacement measurement transducer. This structure can (undesirably) move, independent of the pendulum structure, and produce spurious results.

Inverted pendulum thrust stands are less stable, and hence more sensitive than the hanging pendulum configuration. They have been widely implemented to measure the performance of thrusters over a broad range of $T / W$; resistojets, electrothermal arcjets, MPD thrusters $[3,8,11]$, Hall thrusters [1,5,16], and ion thrusters. One problematic issue with the inverted pendulum configuration is that its stability is a strong function of the stiffness of the (supporting) flexures, and considerable attention must be made to assure that the properties of the flexures do not change during the course of a test (due to, for example, heating) to avoid drift of the baseline displacement (i.e., zero drift).

Unlike both the conventional and inverted pendulum configurations, the restoring force in the torsional pendulum configuration (which rotates about an axis that is parallel to the gravity vector) can be made independent of the thruster mass. Consequently, torsional pendulum thrust stands provide the highest sensitivity, and have recently been implemented in micropropulsion performance evaluation $[9,10,12-15]$. They have also been shown to be effective in measuring the performance of pulsed thrusters $[7,17,18]$. The primary disadvantage of the torsional pendulum configuration is that the horizontal, asymmetric arrangement of its members can be difficult to arrange in a vacuum chamber.

The thrust stand described in the present work is a variant of the conventional pendulum. A new mechanical linkage system that translates horizontal displacement into vertical displacement was implemented, which provides three significant benefits: the sensitivity is independent of the length of the pendulum arm, the sensitivity can be continuously adjusted by a simple rotation of one of the linkage elements, and no independent reference structure is required. Also, two new thrust stand subsystems were demonstrated: high-resolution, light-based non-contact ratiometric position sensing, and an on-board leveling control system.

In the next section of the paper we provide thrust stand design and operation details. Section III describes thrust measurements obtained using a $1 \mathrm{~kW}$ Hall thruster.

\section{System Overview}

The Variable Amplification Hanging Pendulum with Extended Range (VAHPER) thrust stand was designed enable accurate thrust measurement for a variety of electric propulsion devices. The structural members were designed to support large thrusters weighing up to $50 \mathrm{~kg}$ (with $\sim 1 \mathrm{~N}$ thrust levels), while also providing adequate sensitivity for testing small $(\sim 1 \mathrm{~kg})$ thrusters (with $1 \mathrm{mN}$ thrust levels). To accomplish these goals, the conventional pendulum configuration was augmented with a balance mechanism that enabled both variable sensitivity and compact construction, and a modern, non-contact precision position sensor was implemented to provide high resolution deflection measurements. Also, the thrust stand was designed to control zero drift associated with thermal loads and/or external facility mechanical movements through the use of heat exchangers and an on-board leveling control system.

The major components of the VAHPER thrust stand are illustrated in Fig. 1; a description of each component is given below.

\section{A. Balance mechanism}

The balance mechanism is the heart of the VAHPER thrust stand. Horizontal deflections of the hanging pendulum (bottom) are converted into (amplified) vertical deflections by a linkage system at the top of the thrust stand. The height of the entire apparatus, from the bottom of the pendulum to the top of the displacement transducer, is approximately $2 \mathrm{~m}$.

The principal of operation of the pendulum-balance system is illustrated in Fig. 2. The configuration of the balance mechanical members are shown in two positions: 


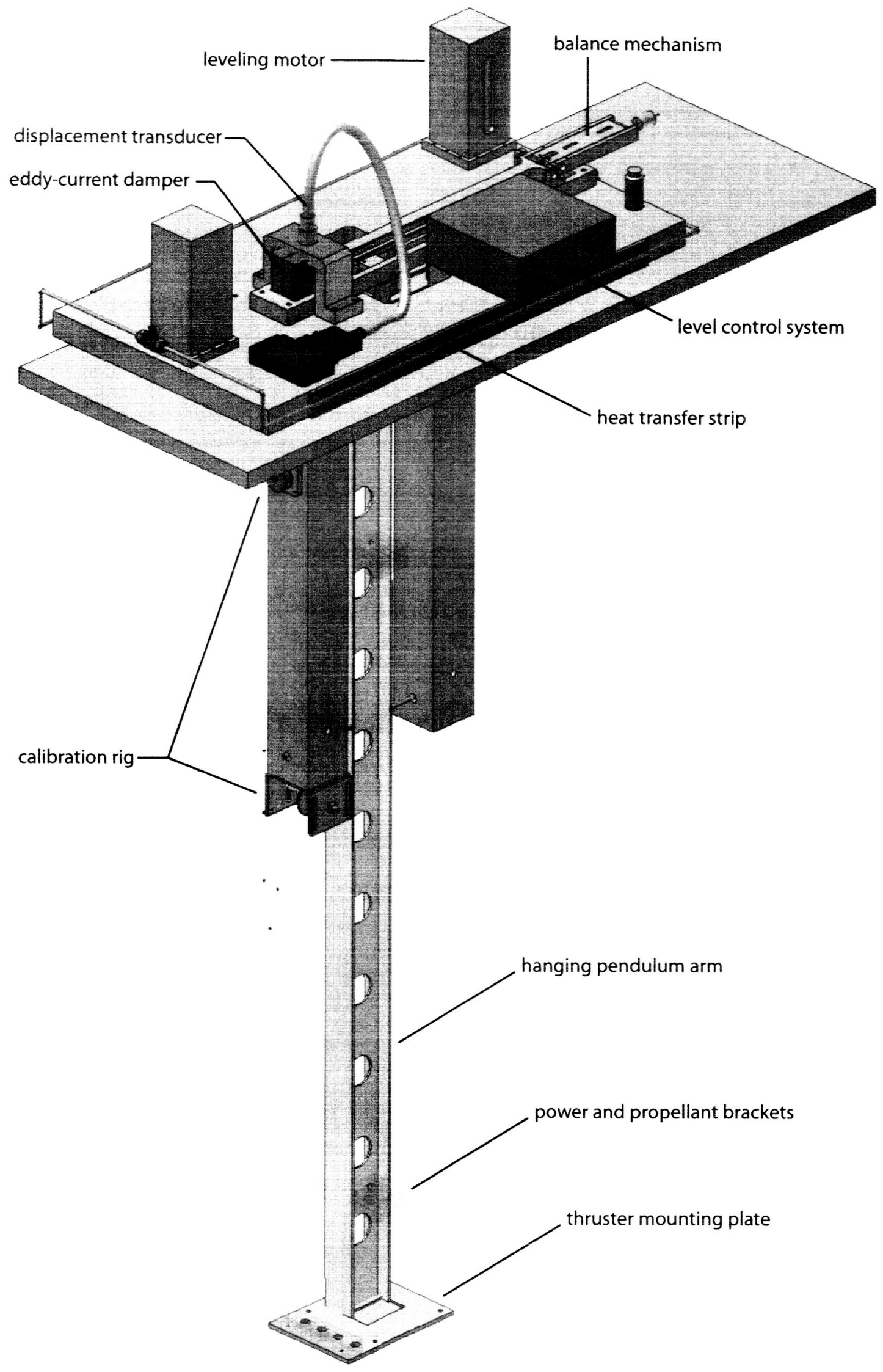

Figure 1 Schematic illustration of the VAHPER thrust stand components. 


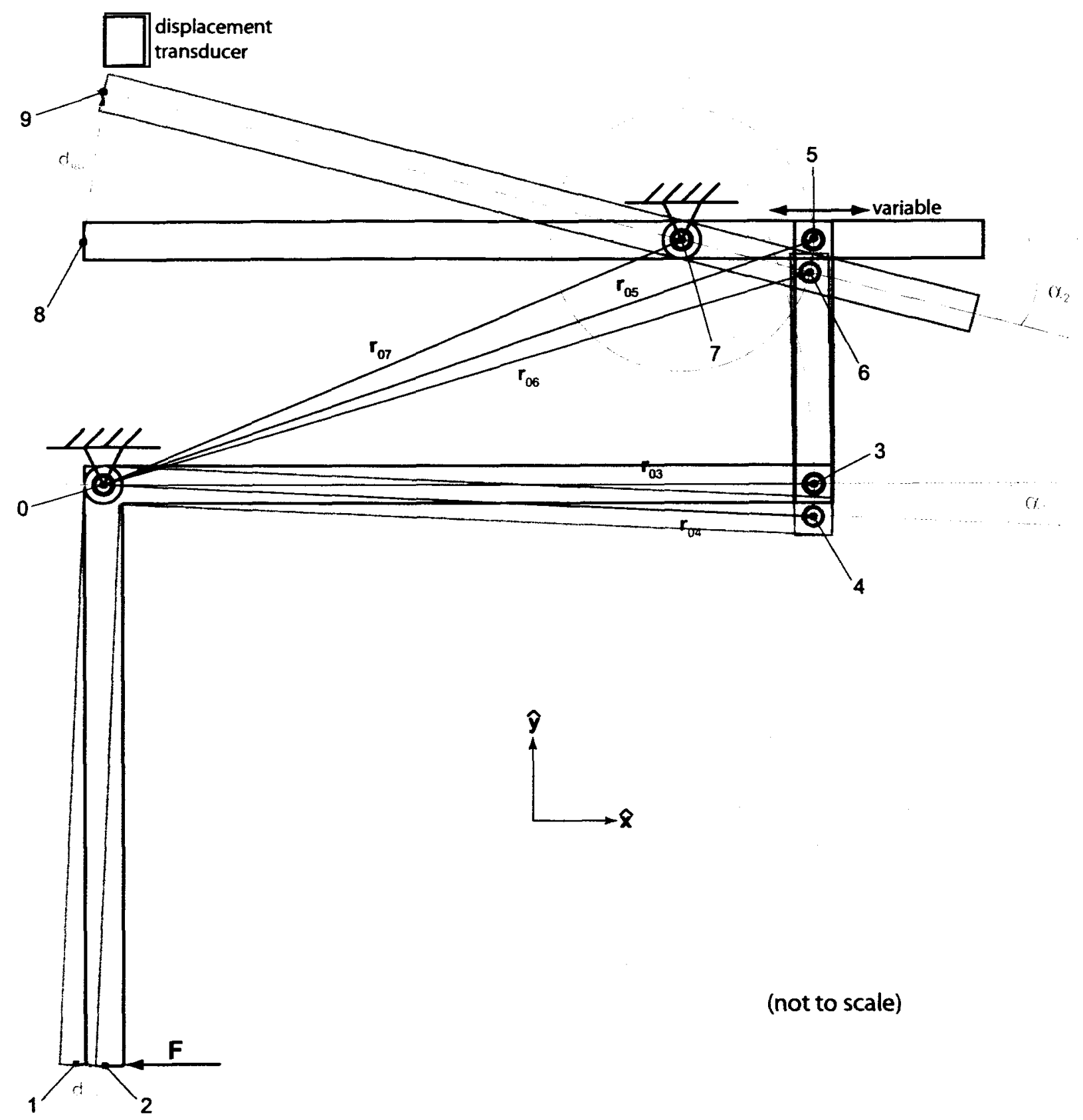

Figure 2 Schematic illustration of balance mechanism components and displacement calculation vectors.

the black outline represents the unloaded position of the members; the grey outline represents the deflected position of the members - after application of the force $F$. Vectors, angles, and points on the structure that are relevant to the deflection analysis are also shown.

The VAHPER thrust balance consists of a two beam system. Displacement of the main beam (the hanging pendulum, illustrated between points 0 and 2 in the figure) causes the (rigidly attached) member between points 0 and 3 to rotate about point 0 . A linkage (between points 3 and 5) connects the main beam to the secondary beam (which rotates about point 7). As point 3 is displaced downward to point 4 , the linkage moves point 5 to position 6 . All of the points are constrained to rotate about the rigidly fixed points 0 or 7 , as indicated by the green arcs in the figure. As point 5 is displaced to point 6 , point 8 is displaced to position 9. As is evident in the figure, the net effect of the 
linkage system is to convert a relatively small horizontal displacement at the base of the hanging pendulum $\left(d_{12}\right)$ into a relatively large displacement vertical displacement $\left(\mathbf{d}_{89}\right)$. The displacement transducer is located near the end of the secondary beam, where the deflection (and hence the thrust level sensitivity) is the greatest. The VAHPER configuration reference structure is the carrier for the pendulum and beam pivots, thus eliminating the need for a separate (problematic) reference structure at the bottom of the pendulum, as is required in a conventional pendulum thrust stand.

All of the balance pivot points utilize frictionless torsional flexures, manufactured by C-Flex Bearing Corporation. The maximum testable thruster mass, $125 \mathrm{~kg}$, is limited by the load capacity of the hanging pendulum bearings (at point 0 ). The restoring force of the flexures is negligible in comparison to the gravitational restoring force associated with the vertical displacement of the test article (i.e., the thruster and associated components). The pendulum arm is made of rigid fiberglass channel, which can easily bear the $125 \mathrm{~kg}$ maximum load.

The response of the thrust stand, that is, the magnitude of the measured displacement $d_{89}$ versus the hanging pendulum displacement $d_{12}$ can be calculated exactly by noting that the length of the inter-beam connecting linkage (initially between points 3 and 5) is constant, and its endpoints are constrained to move in arcs centered at points 0 and 5 . If we adopt the notation $l_{i j}$ as being the length between points $i$ and $j$, then the previous statement can be written in terms of the relevant position vectors:

$$
\left|\mathbf{r}_{05}-\mathbf{r}_{03}\right|=\left|\mathbf{r}_{06}-\mathbf{r}_{04}\right|=l_{35}=\text { constant }
$$

When the physical dimensions of the VAHPER balance structural components are used to specify the components of the vectors in Eqn. 1, the deflection angle $\alpha_{2}$ can be solved for iteratively, and the deflection $\mathbf{d}_{89}$ components can be easily evaluated using the calculated value $\alpha_{2}$ and the known length $l_{78}$.

The physical separation between points 5 and $7,1_{57}$, is continuously adjustable between 5 to $30 \mathrm{~mm}$. This degree of freedom enables the VAHPER thrust stand to provide variable sensitivity. Using the dimensions of the VAHPER balance structural members, in Fig. 3 we have plotted displacement amplification (that is, $\left|\mathbf{d}_{89}\right| /\left|\mathbf{d}_{12}\right|$ ) over the range that $1_{57}$ can be adjusted. It is seen that the VAHPER balance mechanism can amplify thrust-derived deflections of the hanging pendulum up to two orders of magnitude.

It is instructive to consider the simplified, limiting case of small angular displacements, which yields:

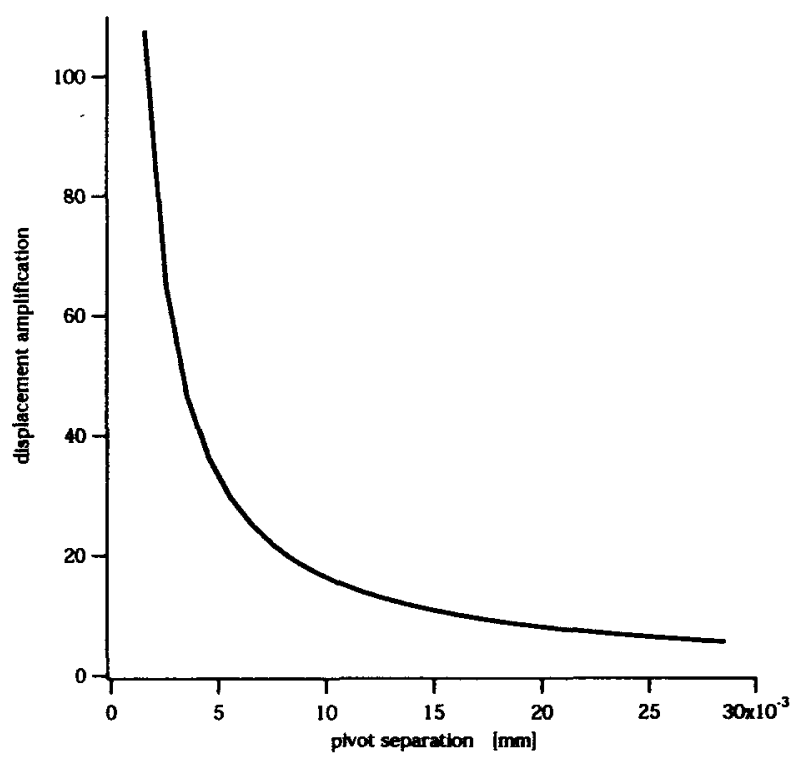

Figure 3 Displacement amplification versus pivot separation, $1_{57}$.

$$
\begin{aligned}
\left|\mathbf{d}_{89}\right| & =\left(\frac{l_{78}}{l_{57}}\right)\left|\mathbf{d}_{56}\right| \\
\left|\mathbf{d}_{56}\right| & =\left|\mathbf{d}_{34}\right| \\
\left|\mathbf{d}_{34}\right| & =\left(\frac{l_{03}}{l_{02}}\right)\left|\mathbf{d}_{12}\right| \\
\left|\mathbf{d}_{12}\right| & =l_{02} \alpha_{1} \\
\Rightarrow\left|\mathbf{d}_{89}\right| & =\left(\frac{l_{78} l_{03}}{l_{57}}\right) \alpha_{1}
\end{aligned}
$$

Since, for a simple pendulum,

$$
\alpha_{1}=\tan ^{-1}\left(\frac{|\mathbf{F}|}{m g}\right)
$$

Eqn. 6 shows that the displacement of the secondary beam, at the location of the displacement sensor, is independant of the hanging pendulum length, that is, in contrast to a conventional hanging pendulum thrust stand, the sensitivity of the VAHPER thrust stand is not a function of the pendulum length.

We can also evaluate the sensitivty limits and bounds on measureable T/W for the VAHPER thrust stand. Equations 6 and 7 are valid for resolution analysis, since only very small displacements are considered. The resolution of the displacement sensor (discussed in the next section) is 1.3 $\mu \mathrm{m}$; however, with our current 12-bit A/D converter, the system resolution is limited to about $13 \mu \mathrm{m}$. Substituting this value for $\left|\mathbf{d}_{89}\right|$, along with the known balance member lengths, into Eqns. 6 and 7 yields:

$$
|\mathbf{F}|_{\min }=9.2 \times 10^{-4} 1_{57} \mathrm{~m}_{\mathrm{t}}
$$


Similarly, since the maximum linear range of the displacement transducer is $8.5 \mathrm{~mm}$, the maximum measurable force is:

$$
|\mathbf{F}|_{\max }=1.3 \times 10^{-1} \mathrm{l}_{57} \mathrm{~m}_{\mathrm{t}}
$$

Substituting the minimum linkage pivot separation distance $\left(1_{57}=5 \mathrm{~mm}\right)$ into Eqn. 8, and the maximum linkage pivot separation $\left(l_{57}=30 \mathrm{~mm}\right)$ into Eqn. 9, establishes the lower and upper bounds for the measurable thrust levels, as shown in Fig. 4.

The figure shows that the VAHPER thrust stand resolution is on the order of $100 \mu \mathrm{N}$, and that it is capable of measuring thrust levels up to the order of $1 \mathrm{~N}$. We note that this level of resolution may not be attainable in an actual test, since facility-specific sources of noise (such as mechanical pump vibrations and thruster EMI) may limit the low-end resolution. Still, we are confident that accurate measurements can be made over the Extended Range of $10^{-3}-1 \mathrm{~N}$ (which motivates the "ER" in "VAHPER").

\section{B. Displacement sensing}

Position sensing of the secondary balance beam displacement (see Fig. 1) was accomplished using a BEI Precision Systems Linear Gap Displacement Transducer (LGDT) with the model LERR probe. The LGDT illuminates the target surface with an IR LED through a concentric-ring fiber-optic probe. Light reflected from the target is analyzed using a ratiometric technique to derive the distance to the target surface. The analog voltage output of the LGDT varies with the distance from the target to the tip of the probe. In addition to the benefit of non-contact measurement, the LGDT is relatively immune to external electric, RF, and magnetics fields - which are ever-present near electric propulsion devices.

The LGDT used on the VAHPER thrust stand has the following specifications: resolution $=1.3 \mu \mathrm{m}$, sensitivity $=$ $0.75 \mathrm{mV} / \mu \mathrm{m}, 1 \%$ linear range $=8.5 \mathrm{~mm}$, and the probe can be positioned 10.0-23.3 $\mathrm{mm}$ from the target surface. The analog output of the probe was digitized and recorded using a National Instruments model 1601 12-bit A/D converter, which dropped the total system sensitivity to about $13 \mu \mathrm{m}$.

\section{Level control system}

Zero drift of the displacement sensor signal is a ubiquitous problem in thrust measurement systems, deriving primarily from unsteady thermal loads and vacuum tank deflections during the course of a test. We have included a level control system in the VAHPER thrust stand design, to both sense and counteract deflections of the structure

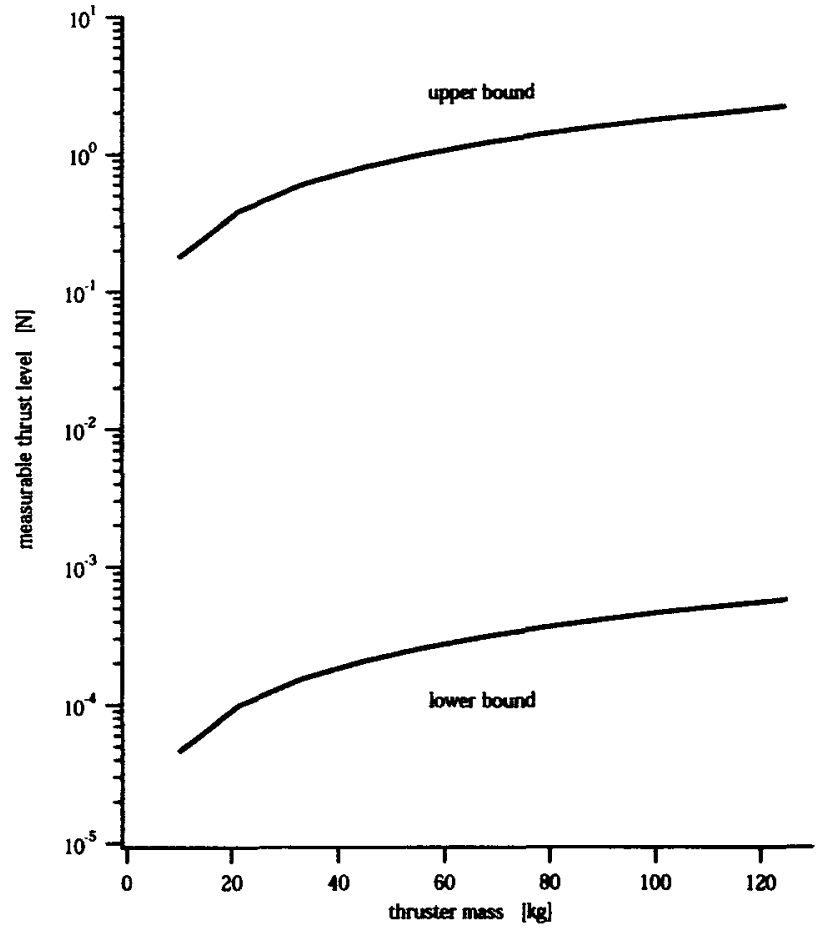

Figure 4 Range of measurable thrust levels versus thruster mass for the VAHPER thrust stand.

that supports the balance mechanism, with the aim of minimizing the zero drift during tests.

The level control system consists of an inclinometer, two linear displacement stepper motors to provide two-axis adjustment capability, and an on-board microprocessor to coordinate the measured level changes with the corrective action of the stepper motors. All of the components are collocated with the balance mechanism on a thick (1.5") aluminum plate, as shown in Fig. 1.

The Thrust Stand Auto-Leveler Board (see Fig. 5) is an allsystems-on-a-board design to allow reading of the dual axis accelerometer, movement of 3 stepper motors, and reading of 4 limit switches for autonomous precision leveling and calibrating. The heart of this unit is the Analog Devices ADXXX dual axis accelerometer. Based on MEMS technology, this device provides a $+/-2 \mathrm{G}$ range and has micro $G$ resolution. This allows the unit to be a very sensitive level sensor for our purpose. The output of this unit is a square wave with a varying duty cycle to represent the $\mathrm{G}$ load. This square wave is centered at $50 \%$ when in a perfectly flat position with respect to earth, for both axes. The output of the accelerometer is continuously monitored by an OOPic chip (a product of Savage Innovations) - a single chip computer designed to allow rapid program development for a wide array of applications. The OOPic chip communicates to an external PC through either a 


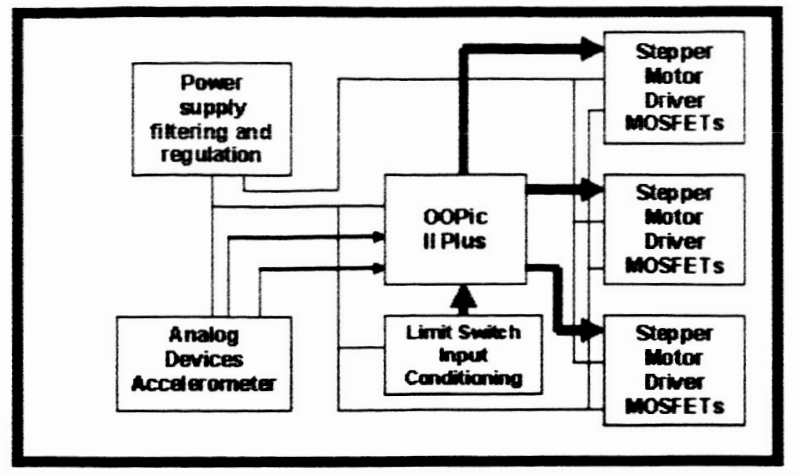

Figure 5 Block diagram of the thrust stand auto-leveler board.

wired or fiber optic RS-232A communications port. The PC Labview control system interrogates the Thrust Stand Auto-Leveler Board to read the accelerometer to determine tilt error in both axes. The computer then sends movement commands back to the OOPic, which then controls the two stepper motor precision jack screws to correct for the tilt error. A third stepper motor is also controlled by the OOPic chip, for the calibration process (which is discussed in a later section).

\section{Damping}

The VAHPER balance mechanism utilizes frictionless flexural pivots; therefore, mechanical oscillations induced by thrust fluctuations or external structural vibrations would persist, and make steady-state measurements difficult. To counteract this effect, we implemented a passive, eddy-current damper, which provides frictionless dissipation of mechanical energy. The device was located at the end of the balance secondary beam, near the displacement sensor. Four $3 / 8$ " diameter samarium-cobalt permanent magnets were imbedded in a soft iron yoke, as pictured in Fig. 6. Opposing magnets were separated by a $1 / 8$ " slot, providing a magnetic field strength of about 0.2 Tesla. A $1 / 16$ " thick copper plate, attached a one end to the secondary beam, extended into the slot between the four permanent magnets.

Vertical mechanical motion of the secondary beam causes the copper plate to move relative to the static magnetic field, inducing eddy-currents in the copper and consequent dissipation of energy. The VAHPER thrust stand eddycurrent damper has proven to be quite effective - providing near critical damping of displacement perturbations.

\section{E. Thermal management}

A closed-loop thermal management system was implemented, with the goal of maintaining a constant balance temperature during tests, in order to minimize displace- ment zero drift. The balance mechanism was mounted on a thick (1.5"), water-cooled aluminum plate (see Fig. 1), to provide high thermal inertia. Thermocouples were attached to both the front and back of the balance. The measured temperatures were used as feedback in a temperature control loop; the circulating coolant temperature was continuously adjusted to compensate for variations in thermal loading. The water flow was maintained by a Thermo Neslab M150 programmable water chiller, which was capable of removing up to $5 \mathrm{~kW}$ of heat power.

\section{F. In-situ calibration rig}

Displacement (thrust) calibration was accomplished by applying a series of known loads normal to the pendulum arm, and recording the resulting displacement of the secondary balance beam. A set of five known masses were attached at regular intervals to along a Kevlar string (see Fig.1). The string was wound around a spool and attached to a stepper motor; the weights could be raised or lowered by remotely operating the stepper motor. The bottom end of the string was draped over a low-friction pulley and attached to the hanging pendulum arm. As the weights were lowered, the string-mass-pulley system transferred the gravitational force on the weights to the thrust stand, normal to the pendulum arm.

The calibration procedure was automated so that at any given time, the calibration weights could be lowered and retracted to provide continuous checks on the displacement calibration. During thruster tests, calibration data was obtained at several times before, during, and after thruster firing.

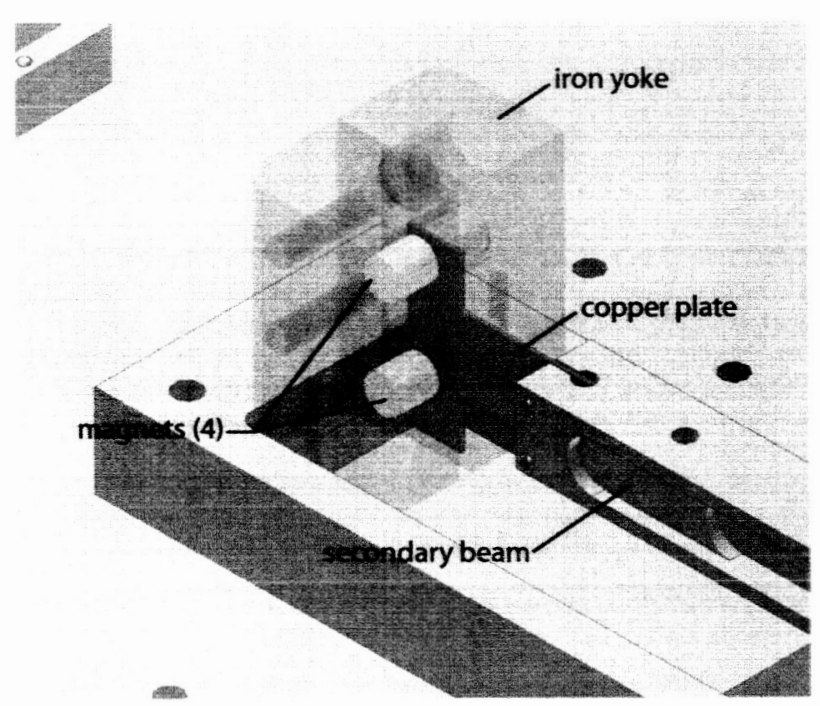

Figure 6 Eddy-current oscillation damper illustration (note: iron yoke has been rendered transparent to reveal inner detail). 


\section{G. Data acquisition and control}

All VAHPER thrust stand systems were monitored and controlled using a National Instruments Labview interface. National Instruments Fieldpoint modules were used for data acquisition: a 12-bit, $10 \mathrm{kHz}$ module was used to acquire the output from the LGDT, and thermocouple output was acquired using a cold-junction-compensated module.

\section{Thruster Testing}

\section{A. Facility}

The thrust stand was mounted in a $12 \mathrm{ft}$ X $20 \mathrm{ft}$ vacuum tank that has been equipped for testing electric propulsion devices (see Fig. 7). The facility uses six 32 inch diffusion pumps capable of pumping up to 180,000 liters/sec. To compliment the thrust stand measurements, a suite of diagnostic equipment is available for plume interrogation including: laser induced fluorescence, magnetic and electric field probes, Langmuir probes, microwave and laser interferometry.

\section{B. $1 \mathrm{KW}$ Hall thruster test}

We tested a thruster with well characterized performance in order to benchmark the thrust measuring capabilities of the VAPHER thrust stand. A Busek BHT-1000 Hall thruster, and the associated power and gas feed lines, were attached to the thrust stand (see Fig. 7). The balance was configured for its least sensitive setting $\left(1_{57} \sim 30 \mathrm{~mm}\right)$.

LGDT output, balance pitch and roll tilt angles, and temperature were recorded throughout the duration of the tests. Figure 8 shows typical raw data from the displacement sensor. The loading and unloading of the five calibration weights is seen in the stair-stepped feature near $\mathrm{t} \sim 500 \mathrm{~s}$. At about $\mathrm{t} \sim 1000 \mathrm{~s}$, the thruster startup procedure began. The cold gas flow was initiated, and cathode heaters were turned. Some deflection of the thrust stand is evident during the pre-discharge startup procedure. At about $\mathrm{t} \sim 2100$ $s$ the main discharge was initiated. The LGDT voltage is seen to drop about $4 \mathrm{~V}$ from its initial value; this is about $40 \%$ of the full range of the sensor. The displacement, and hence the thrust, is seen to be steady over the next $2000 \mathrm{~s}$ of testing.

Table 1 summarizes the performance measurements for a variety of input power levels. The error bars on the specific impulse and thrust efficiency are estimated to be $\pm 5 \%$. These measurements are consistent with previously reported values [19]. For example, the reported peak anode efficiency is $54 \%$, which is in-line with our measurements.

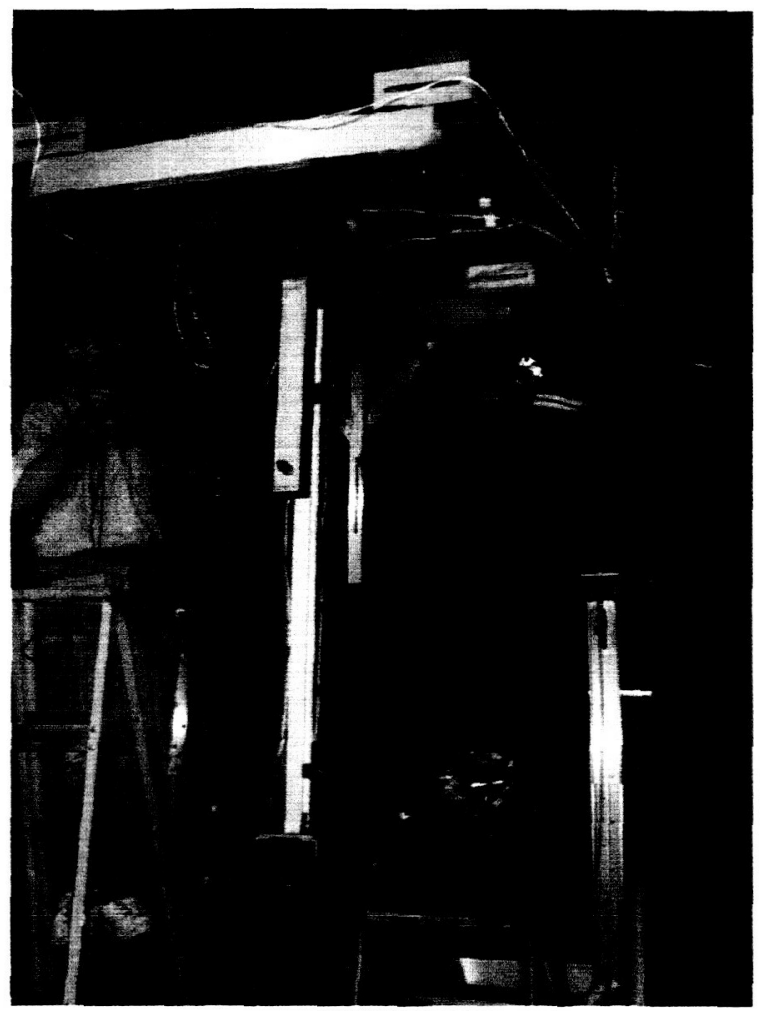

Figure 7 Hall thruster mounted on VAHPER thrust stand, in preparation for testing.

\section{Conclusions and Future Work}

We have developed a hanging pendulum thrust stand, augmented with a mechanical linkage system, which enables adjustable amplification of thrust-derived pendulum deflection. Furthermore, unlike conventional hanging pendulum thrust stands, the deflection is independent of the length of the pendulum arm, and no reference structure is required at the end of the pendulum. The thrust stand is capable of measuring thrust levels ranging from $1 \mathrm{mN}$ to 1 $\mathrm{N}$, and supporting thrusters of up to $125 \mathrm{~kg}$ total mass.

Several supporting systems have been implemented to enhance the measurement accuracy: high-sensitivity, noncontact displacement sensing, an automated leveling system, an oscillation damping device, and thermal control. An in-situ calibration rig enables calibration at any time during testing.

A series of experiments with a well characterized thruster validated the capability of the thrust stand to measure thrust. Our immediate plans are to test additional well characterized thrusters at different T/W to verify the thrust stands extended range capability. This will also test the thrust stands capability for adjustable amplification, as predicted in Fig. 3.

8

American Institute of Aeronautics and Astronautics 


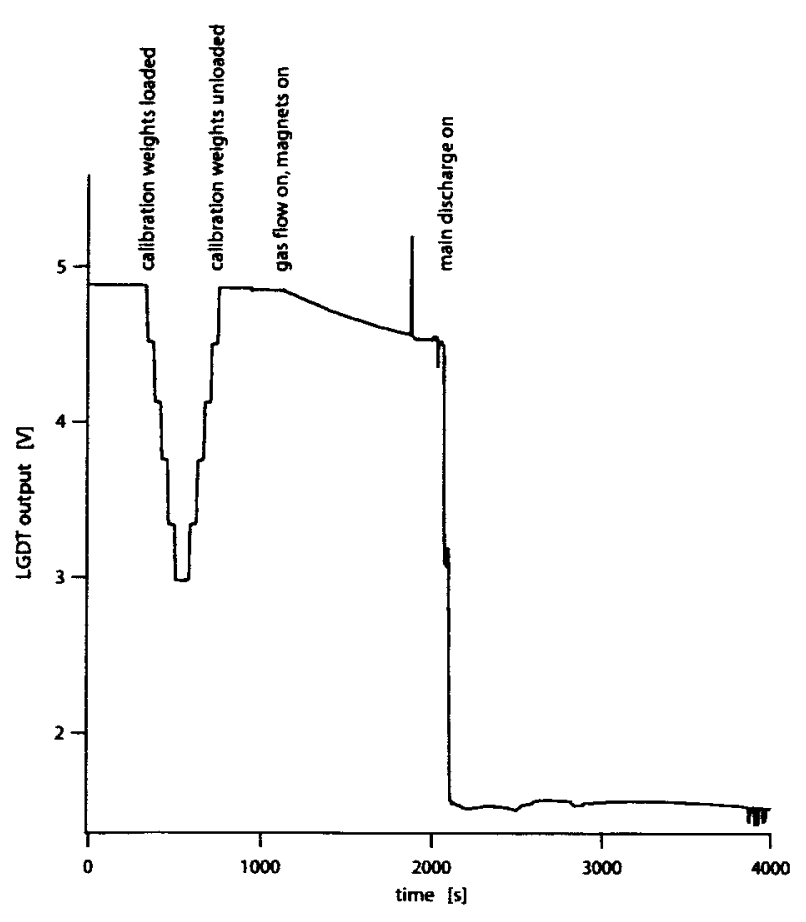

Figure 8 Raw data from Hall thruster test showing position sensor output versus tine.

\section{Acknowledgements}

We thank the PRC management, Drs. Stephen Rodgers, Charles Schafer, and Jeffrey Sheehy, for encouragement and support. We appreciate the CAD and graphics support provided by Winford Davis of Alabalma A\&M. We gratefully acknowledge the invaluable contributions of the PRC In-Space Propulsion Group technical support staff: Doug Davenport, Doug Galloway, Mike Lee, Tommy Reid, Jeff Richeson, Keith Chavers, and Dexter Strong. We thank Busek Co. for the loan of the Hall thruster. We extend our gratitude to Todd Schneider and Jason Vaughn of the MSFC Engineering Directorate for assistance in operating the Busek Hall thruster during the thrust tests.

\section{References}

[1] M.A. Cappelli, Q.E. Walker, and N.B. Meezan. Performance of a Linear Hall Discharge with an Open Electron Drift. In 37h Joint Propulsion Conference, Salt Lake City, Utah, July 8-11 2001. AIAA 2001-3503.

[3] F. Paganucci, P. Rossetti, and M. Andrenucci. Performance of an Applied Field MPD Thruster with a Pre-ionization Chamber. In $33^{\text {rd }}$ Plasmadynamics and Lasers Conference, Maui, Hawaii, May 20-23 2002. AIAA 2002-2103.

[4] K.D. Diamant and R.B. Cohen. High Power Microwave Electrothermal Thruster Performance on Water. In $38^{\text {th }}$ Joint Propulsion Conference, Indianapolis, Indiana, July 7-10 2002. AIAA 2002-3662.

D. Manzella, R. Jankovsky, and R. Hofer. Laboratory Model $50 \mathrm{~kW}$ Hall Thruster. In $38^{\text {th }}$ Joint Propulsion Conference, Indianapolis, Indiana, July 7-10 2002. AIAA 2002-3676.

[6] K.D. Diamanc, J.E. Brandenburg, R.B. Cohen, and J.F. Kline. Performance Measurements of a Water Fed Microwave Electrothermal Thruster. In $37^{\text {th }}$ Joint Propulsion Conference, Salt Lake City, Utah, July 8-11 2001. AIAA 2001-3900.

[7] T.W. Haag. "Thrust stand for pulsed plasma thrusters." Rev. Sci. Instrum.,Vol. 68, No. 5, May 1997.

Table 1 Performance of BHT-1000 Hall as measured by VAPHER thrust stand.

\begin{tabular}{cccccccc}
\hline \hline $\begin{array}{c}\text { Discharge } \\
\text { Power [W] }\end{array}$ & $\begin{array}{c}\text { Discharge } \\
\text { Current [A] }\end{array}$ & $\begin{array}{c}\text { Discharge } \\
\text { Voltage [M] }\end{array}$ & $\begin{array}{c}\text { Anode } \\
\text { Flow Rate } \\
{[\mathrm{mg} / \mathrm{s}]}\end{array}$ & $\begin{array}{c}\text { Cathode } \\
\text { Flow Rate } \\
{[\mathrm{mg} / \mathrm{s}]}\end{array}$ & $\begin{array}{c}\text { Thrust } \\
{[\mathrm{mN}]}\end{array}$ & $\begin{array}{c}\text { Anode } \\
\text { Specific } \\
\text { Impulse [s] }\end{array}$ & $\begin{array}{c}\text { Anode } \\
\text { Thrust } \\
\text { Efficiency } \\
{[\%]}\end{array}$ \\
\hline 358.50 & 1.5 & 239 & 1.79 & 0.30 & 22.4 & 1278 & 0.39 \\
587.94 & 2.46 & 239 & 2.87 & 0.30 & 40.9 & 1452 & 0.50 \\
816.34 & 3.43 & 238 & 3.89 & 0.30 & 58.6 & 1537 & 0.54 \\
854.07 & 3.43 & 249 & 3.89 & 0.30 & 60.2 & 1579 & 0.55 \\
998.13 & 3.43 & 291 & 3.89 & 0.30 & 65.3 & 1712 & 0.55 \\
\hline \hline
\end{tabular}


[8] T.W. Haag. "Thrust stand for high-power electric propulsion devices.” Rev. Sci. Instrum., Vol. 62, No. 5,May 1991.

[9] E.A. Cubbin, J.K. Ziemer, E.Y. Choueiri, and R.G. Jahn. "Pulsed thrust measurements using laser interferometry." Rev. Sci. Instrum., Vol. 68, No.6, June 1997.

[10] A. Sasoh and Y. Arakawa. "A high-resolution thrust stand for ground tests of low-thrust space propulsion devices." Rev. Sci. Instrum., Vol. 64, No. 3, March 1993.

[11] L.D. Cassady, A.D. Kodys, and E.Y. Choueiri. A Thrust Stand for High-power Steady-state Plasma Thrusters. In $38^{\text {th }}$ Joint Propulsion Conference, Indianapolis, Indiana, July 7-10 2002. AIAA 2002-4118.

[12] A.D. Ketsdever and E.P. Muntz. Facility Effects on Performance Measurements of Micropropulsion Systems. In $37^{\text {th }}$ Joint Propulsion Conference, Salt Lake City, Utah, July 8-11 2001. AIAA 2001-3335.

[13] A.D. Ketsdever, A.A. Green, and E.P. Muntz. Momentum Flux Measurements from Under Expanded Orifices: Applications for Microspacecraft Systems. In $39^{\text {ch }}$ Aerospace sciences Meeting, Reno, Nevada, January 8-11 2001. AIAA 2001-0502.

[14] B. Reed. Decomposing Solid Micropropulsion Nozzle Performance Issues. In $41^{\text {st }}$ Aerospace Sciences Meeting, Reno, Nevada, January 6-9 2003. AIAA 2003-672.

[15] W.D. Willis III, C.M. Zakrzwski, and S.M. Merkowitz. Development of a Thrust Stand to Meet LISA Mission Requirements. In $38^{\text {th }}$ Joint Propulsion Conference, Indianapolis, Indiana, July 7-10 2002. AlAA 2002-3820.

[16] A. Smimov, Y. Raitses, and N.J. Fisch. Performance Studies of Miniaturized Cylindrical and Annular Hall Thrusters. In $38^{\text {th }}$ Joint Propulsion Conference, Indianapolis, Indiana, July 7-10 2002. AIAA 2002-3823.

[17] T.W. Haag. PPT Thrust Stand. In $31^{\text {st Joint }}$ Propulsion Conference, San Diego, Califomia, July 10-12 1995. AIAA-95-2917.

[18] K.W. Stark, T. Dennis, D. McHugh, and T.
Williams. Design and Development of a Micropound Extended Range Thrust Stand. August 1971. NASA TN D-7029.

[19] Busek web site. http://www.busek.com/bht.htm.

[20] Y. Lee, G.N. Kudva, and T.A. Litzinger, "A facility for solid-propellant response measurements under pressuredriven conditions. Measurement Science and Technol ogy, Vol. 11, No. 1, 2000. 